\title{
A Presença de Brasileiros na Recente Colonização do Paraguai
}

\author{
ANDRESSA SZEKUT ${ }^{1}$, \\ Jorge EREMItes De OLIVEIRA ${ }^{2}$
}

\begin{abstract}
Resumo
Neste artigo os autores analisam a presença de brasileiros e paraguaios no processo de colonização recente no município de Santa Rita, localizado no Departamento de Alto Paraná, região Oriental da República do Paraguai, iniciado na década de 1970. O objetivo do trabalho é contribuir para a compreensão das relações sociais entre migrantes estrangeiros e nacionais nesse espaço de colonização. Para este propósito, os autores estabelecem interfaces metodológicas entre os campos da História e da Antropologia Social, conjugando pesquisa bibliográfica, documental e etnográfica para a reflexão sobre a situação histórica observada na região.
\end{abstract}

Palavras-chave: Brasileiros no Paraguai. Colonialismo. História do Paraguai. Processo de colonização.

\section{Brazilians' presence in Recent Paraguay Colonization}

\footnotetext{
Abstract

In this paper the authors analyze Brazilians' and Paraguayans' presence in the process of recent colonization in the municipality of Santa Rita, Department of Alto Paraná, Oriental region of the Republic of Paraguay, initiated in the 1970's. The objective

1 Doutoranda pelo Programa de Pós-Graduação em Memória Social e Patrimônio Cultural da Universidade Federal de Pelotas (UFPel), Brasil. andressaszekut@gmail.com

2 Doutor em História/Arqueologia pela Pontifícia Universidade Católica do Rio Grande do Sul (PUCRS), docente da Universidade Federal de Pelotas (UFPel), Brasil. Bolsista de produtividade em pesquisa do Conselho Nacional de Desenvolvimento Científico e Tecnológico (CNPq). eremites.br@gmail.com.
} 
of the paper is to contribute to the understanding of the social relations among migrants (foreign and national) in that space of colonization. In order to achieve this, the authors establish methodological interfaces between the fields of History and Social Anthropology, conjugating bibliographical, documentary and ethnographic research for a reflection on the historical situation observed in the region.

Keywords: Brazilians in Paraguay. Colonialism. History of Paraguay. Colonization process.

\section{INTRODUÇão}

O presente artigo apresenta um estudo sobre a presença de brasileiros na recente colonização de parte da porção Oriental do Paraguai, precisamente no Distrito de Santa Rita, localizado no Departamento de Alto Paraná, próximo à fronteira com o estado brasileiro do Paraná 3 . Trata-se de um evento oficialmente registrado a partir da segunda metade do século XX, quando o governo do país vizinho estimulou a migração de brasileiros e paraguaios para a região. O tema traz em si certa idiossincrasia e, por este motivo, chama a atenção para a necessidade de haver um posicionamento crítico frente a essencialismos, exotismos e nacionalismos suscitados na mídia e nas redes sociais sobre o assunto. Em termos mais específicos, o que se pretende aqui é contribuir para a compreensão sobre a construção de uma memória social no âmbito das relações sociais estabelecidas entre nacionais e estrangeiros naquela parte do Paraguai.

3 No Paraguai, os termos distrito e departamento são equivalentes aos de município e estado no Brasil. 
Figura 1 - Mapa político atual do Paraguai com seta indicando a localização do Distrito de Santa Rita, no Departamento de Alto

Paraná.

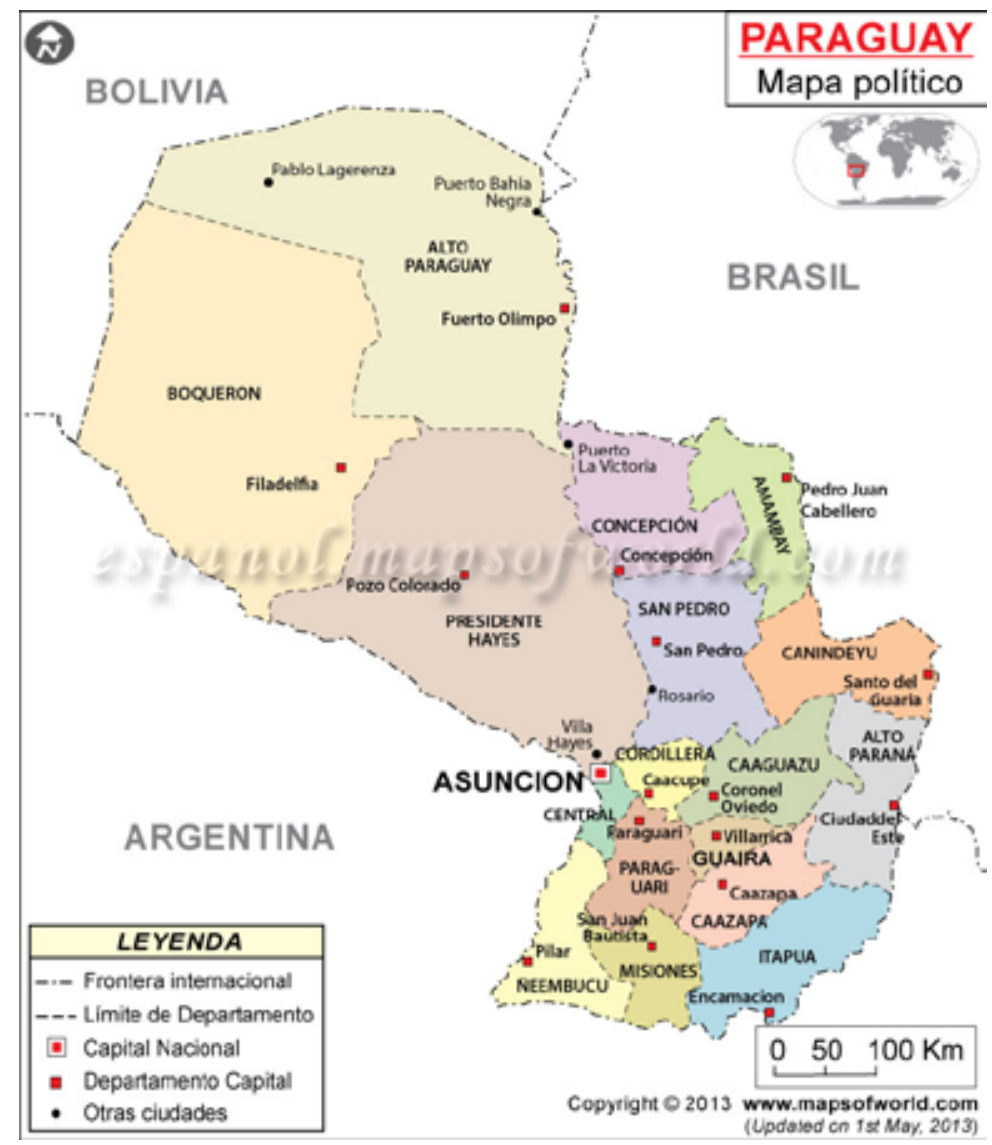

Fonte: Mapas del Mundo (2015).

Para este propósito, parte-se de uma perspectiva metodológica que busca estabelecer interfaces entre os campos da Antropologia Social e da História, especialmente por meio de pesquisa bibliográfica, documental e etnográfica. Considera-se que a etnografia é, ao mesmo tempo, processo e produto, resultado de uma ação de empatia e estranhamento, bem como de proximidade e distanciamento, a envolver pesquisadores e interlocutores (PUJADAS, 2012). Neste 
aspecto em particular, registra-se que o trabalho de campo que embasa o presente estudo foi realizado por uma de nós na cidade de Santa Rita, no período de fevereiro e julho de 2015: realização de mais de cinquenta entrevistas semiestruturadas com migrantes brasileiros e paraguaios e descendentes; levantamento e análise de fontes escritas, como atas públicas e documentos pessoais; registros fotográficos sobre a região; e anotações contínuas da pesquisa em diário de campo, incluindo observações sobre práticas cotidianas, comemorativas e políticas. Os dados aqui apresentados foram analisados sob inspiração dos estudos pós-coloniais, valendo-se de autores conhecidos para o assunto, conforme demonstrado ao longo do trabalho.

A respeito de Santa Rita, faz-se necessário explicar que se trata de um município paraguaio com marcante presença de migrantes brasileiros, como verificado em toda a região, muitos dos quais ali chegaram a partir da década de 1970 (SZEKUT; EREMITES, 2015). Foi emancipado em 1990 e está situado em uma zona que originalmente possuía extensas florestas e terras consideradas produtivas para a expansão do agronegócio. De acordo com dados oficiais e segundo informações obtidas junto a autoridades locais, acrescidas de narrativas registradas durante o trabalho de campo, a região seria desabitada e pouco explorada economicamente até os anos 1960. Esta afirmativa, contudo, bastante recorrente na localidade, exclui a presença e a produção de pequenos camponeses e comunidades indígenas. Ocorre que o discurso relacionado à existência de um suposto vazio demográfico contribui, pois, para a legitimação da ação oficial de colonização, feita de forma compulsória pelo Estado Paraguaio durante o governo ditatorial de Alfredo Stroessner (19541989).

Sobre o assunto, cabe citar uma análise que Frantz Fanon apresenta sobre a colonização em geral, a qual contribui para a 
compreensão da constituição de certa representação sobre a história local:

\begin{abstract}
O colono faz a história e sabe que a faz. E porque se refere constantementeà história de sua metrópole, indica de modo claro que ele é aqui o prolongamento dessa metrópole. A história que escreve não é, portanto, a história da região por ele saqueada, mas a história de sua nação no território explorado, violado e esfaimado. A imobilidade a que está condenado o colonizado só pode ter fim se o colonizado se dispuser a por termo à história da colonização, à história da pilhagem, para criar a história da nação, a história da descolonização (FANON, 1968, p. 38).
\end{abstract}

Segundo Silva (2005) e Souchaud (2007), na época o governo paraguaio buscava o desenvolvimento agrícola e a descentralização da população nacional em relação à capital do país e arredores. Para este propósito, criou o Instituto de Bienestar Rural (IBR), atual Instituto Nacional de Desarrollo Rural y de la Tierra (INDERT), cuja missão estava ligada à organização da colonização pública e privada em terras situadas na parte Oriental do país. Costa (2009, p. 4), por sua vez, explica que para a criação do IBR e também do Estatuto Agrário, o Paraguai teve apoio dos Estados Unidos “através do Programa Alianza para el Progreso 18", momento em que o governo central atuou decisivamente na ampliação da estrutura fundiária nacional. Desde então, o Estado impulsionou a fixação de paraguaios e brasileiros na região, com vistas à expansão das fronteiras agrícolas e, por conseguinte, do agronegócio.

Seguindo o modelo de um projeto implantado no Brasil na época do governo ditatorial de Getúlio Vargas, no período do Estado Novo (1937-1945), conhecido como "Marcha para o Oeste", foi implantado no Paraguai o projeto "Marcha para el Este". Juntamente com esta iniciativa estatal, houve o incentivo à migração brasileira, principalmente de pessoas oriundas da região Sul, muitos dos quais descendentes de migrantes europeus que vieram para o Brasil a partir do século XIX. 
Ocorreram, então, dois movimentos colonizadores no Oriente do Paraguai: um de Oeste para Leste, por parte de uma população majoritariamente paraguaia, iniciado em fins da década de 1950; e outro, de Leste para Oeste, constituído em sua maioria por migrantes brasileiros, cujo fluxo mais significativo ocorreu a partir dos anos 1970. Ambas as frentes se encontraram na região de Santa Rita e adjacências, sendo que cada uma possuía características socioculturais, políticas e econômicas particulares. Entende-se, portanto, que a colonização da parte Oriental do Paraguai, conformada por uma população de diferentes origens, transformou aquele espaço a partir de complexas formas de interações e contatos interétnicos, não necessariamente pacíficos e pautados unicamente pela solidariedade social.

Neste aspecto em particular, chama-se à atenção para o uso que se faz do termo "colonização". Trata-se de um vocábulo oficialmente empregado para se referir ao processo de ocupação territorial recentemente ocorrido na área. $\mathrm{O}$ ato de colonizar está historicamente relacionado a explorações europeias para além-fronteiras, tanto no Ocidente como no Oriente do planeta. Sabe-se que países europeus estabeleceram colônias para a exploração de povos e territórios existentes em outros continentes, como é o caso das Américas, África, Ásia e Oceania. As consequências desse processo se estendem até o tempo presente sob novas formas de colonialismo, incluindo a própria colonialidade do saber e do poder, conforme apontam Cooper (2005), Fanon (1968), Lander (2005), Loomba et al. (2005), Smith (2005), Said (2007) e outros autores situados no movimento pós-colonial.

Por razões dessa natureza, faz-se oportuno apresentar as explicações de Henriques acerca dos termos colonização, colonizar e colonial:

Os termos colonização (o fato de povoar com colonos, de transformar em colônia, de explorar as colônias), colonizar (estabelecer colônia, habitar como colono), e colonial (adjetivo relativo às colônias - expansão colonial, 
regime colonial, produtos coloniais, chapéu colonial) banalizam-se na segunda metade do século XVIII, dando conta sobretudo das situações coloniais americanas (HENRIQUES, 2014, p. 46-47).

Mais:

Registre-se ainda um elemento fundamental que atravessa toda esta problemática: se a colonização significa a eliminação da autonomia do colonizado, não só territorial, mas também cultural - como as línguas e as religiões -, colonizar é um exercício que visa desmemoriar as populações em relação à sua própria história, introduzindo a história do colonizador e construindo uma nova memória, onde uns e outros são hierarquizados de acordo com a ordem do colonizador, marcando de forma definitiva a valorização do mesmo, a desvalorização e a recusa do outro. A violência - nas suas múltiplas facetas inerente à dominação foi sempre uma constante dos processos de colonização (HENRIQUES, 2014, p. 49).

Analisar o tema colonização implica, ainda, em tratar de poder e autoridade, dentre outros assuntos correlatos. No caso aqui abordado, trata-se, sobremaneira, do poder do Estado-nação do Paraguai que incentivou a migração de nacionais e estrangeiros para a constituição das frentes de expansão das fronteiras agrícolas no país. Existem, portanto, diferenças no que se refere à colonização empreendida no Paraguai, na segunda metade do século $X X$, em relação àquela realizada por países europeus para além-mar, do século XV ao XIX, haja visto o contexto histórico e as características econômicas, políticas e socioculturais de cada época e lugar. Contudo, todo tipo de colonização oficial traz em si a marca da violência da intervenção do Estado e da sociedade nacional sobre territórios e populações submetidas ao seu poder, geralmente colocadas em situação de subalternidade e com menos visibilidade social. 
Na década de 1960, González Casanova (2006) analisou situações análogas a partir do paradigma do colonialismo interno, isto é, de um sistema estruturante ligado a relações sociais de poder, exploração e tentativas de dominação. $\mathrm{O}$ citado autor explica que após a independência de várias ex-colônias europeias nas Américas, as elites criollas de matriz euroamericana passaram a desenvolver um colonialismo interno sobre "minorias" indígenas, negras etc. Neste sentido, o fato de antigas colônias tornarem-se Estados-nações não é parâmetro para a inexistência do colonialismo, cujo conceito não está ligado, que se faça bem entendido, a temporalidades do período colonial. No mesmo decênio, Cardoso de Oliveira (1978), baseando-se nas discussões feitas pelo referido autor e nos aportes de Balandier (1993), publicados nos anos 1950, dentre outros, discute a noção de colonialismo interno a Etnologia. Assim o faz chamando à discussão para a necessidade de abordar o assunto com vistas a conhecer o Brasil indígena. Nesta linha de raciocínio, considera-se, por exemplo, a ação do colonialismo interno na expulsão de coletivos humanos de seus territórios tradicionais diante de ações das frentes de expansão econômica das sociedades nacionais, como verificado em vários países americanos.

Diante do exposto, faz-se necessário esclarecer que neste trabalho, também são consideradas as experiências pessoais de cada um dos autores: uma pesquisadora nascida na região Sul do Brasil e que, quando criança, migrou com sua família para o Paraguai e lá fez os estudos equivalentes ao ensino fundamental e médio; um pesquisador brasileiro que desde os anos 1990 mantém relações profissionais com pesquisadores paraguaios, tendo realizado vários estudos sobre a história dos povos indígenas na região platina. Deste encontro entre pessoas que transitam por diferentes fronteiras (territoriais, disciplinares, étnicas etc.), surgiu uma profícua parceria 
para a realização de estudos sobre a migração brasileira para o território paraguaio, parte dos quais é aqui apresentada.

\section{O Paraguai e a Recente Colonização Oficial}

No que diz respeito à recente colonização oficial do Paraguai, Carrón e Silva (2006) explicam o processo histórico ligado à situação política e econômica verificada no país, marcado pela violação de direitos e esquemas de corrupção. Esta situação histórica tem reflexos na gestão do território nacional e na privatização de terras públicas. No fim do século XIX, o Estado paraguaio vendeu grande quantidade de terras a alguns indivíduos, geralmente estrangeiros que não se fixaram no país e para lá inicialmente não impulsionaram grandes fluxos migratórios. Com isso, muitos camponeses foram obrigados a deixar suas terras e migrarem para Assunção e circunvizinhanças, ou mesmo a permanecerem em seus locais de origem na condição de empregados ou arrendatários. Assim dizem os referidos autores:

Entre 1956 y 1981 pareció que algo cambiaría en el campo. El gobierno promovió un proceso de colonización y de expansión de la frontera agrícola, desordenado e incompleto, pero que mejoró ciertos indicadores agrarios. La proporción del territorio nacional destinada a la agricultura pasó del 2\% al 7\%. Donde predominaba una gran proporción de explotaciones agrícolas minifundistas, radicalmente incapaces de proporcionar sustento a una familia, apareció una faja de campesinos que explotaban lotes de 10 a 20 hectáreas. Entre 1956 y 1981, el número de este tipo de explotaciones sufrió más que una duplicación. Sobre todo se incrementó, en el mismo período, el número y la superficie cubierta por explotaciones de 20 a 99,9 hectáreas, que pasó de 15.819 a 50.018 , y de 524.204 hectáreas a 1.419.437 (CARRÒN; SILVA, 2006, p. 11).

A explicação apresentada chama a atenção para certos aspectos positivos que a "Marcha para el Este" teria propiciado à população paraguaia. No entanto, em um primeiro momento não considera, por 
exemplo, eventuais violações dos direitos de povos indígenas, cujos territórios estavam inseridos em áreas objeto de colonização. Com as políticas de incentivo à agricultura no interior do país, inicialmente é verificado um baixo fluxo migratório rumo ao Oriente, haja vista que somente a partir dos anos 1970 ocorre um fluxo expressivo de migrantes do Brasil para a região. Este processo ocorreu no âmbito da abertura da economia do Paraguai para o mundo, sendo que naquele decênio a população de brasileiros ali estabelecidos foi estimada em 34.276 pessoas (CARRÓN; SILVA, 2006, p. 13).

Em 1967, o Estado Paraguaio revogou a lei que proibia a compra por estrangeiros de terras na faixa de $150 \mathrm{~km}$ de suas fronteiras. Essa medida facilitou a migração para o país e fortaleceu as relações com o Brasil, algo que era fomentado, como pode ser observado, em várias ações implementadas na segunda metade do século $X X$, tais como: edificação da Ponte Internacional da Amizade (1962); fundação da cidade de Presidente Stroessner (1957), posteriormente chamada de Ciudad del Este (1989); construção da Ruta Nacional 7, rodovia que liga esta cidade a Assunção, também conectando-se com a rodovia brasileira BR-277, no estado do Paraná; assinatura da Declaração de Assunção (1971), do Tratado de Itaipu (1973) e do Tratado de Amizade e Cooperação (1975).

Além de ter sido incentivada pelo governo, a migração de brasileiros para o Paraguai está associada ao que Carrón e Silva (2006) - parafraseando Hervé Thery (2004) - chamam de "tsunami de la soja". Trata-se do processo de expansão das fronteiras agrícolas e, consequentemente, do agronegócio, frente a demandas do mercado globalizado para a produção de soja (Glycine max). Neste contexto mais amplo, o governo paraguaio incentivou a migração de brasileiros, especialmente pessoas oriundas da região Sul do Brasil, muitas delas descendentes de migrantes europeus e consideradas experientes para 
este propósito, pois estariam inseridas no processo de expansão das fronteiras agrícolas desde longa data.

Nota-se, com efeito, que a organização das colonizadoras para o processo de colonização oficial empreendido no Brasil durante o Estado Novo (GREGORY, 2002) serviu de inspiração para a colonização do Paraguai. Percebe-se, nesse país, a reprodução de modelos implantados anteriormente no Norte e Oeste do estado do Paraná: subsídios, direcionamento na venda das terras e formação de uma colônia inicialmente constituída por pequenas propriedades. Ações desse tipo resultam no surgimento de municípios no departamento de Alto Paraná: Naranjal, Santa Rosa del Monday, Santa Rita e outros, onde há forte presença de brasileiros e descendentes (ver MARTINS, 1996; FABRINI, 2012; e outros). Muitas dessas pessoas são oriundas do Rio Grande do Sul, passaram pelo Paraná e depois se fixaram no Paraguai, como ocorre em Santa Rosa del Monday (MARTINS, 1996), município limítrofe ao de Santa Rita.

Percebe-se ainda a prevalência desse padrão de organização para a colonização de Santa Rita, instaurada pela empresa colonizadora Itaipu Amalisa, sob a coordenação de Adelino Vettorello (BACK, 2014). De acordo com as narrativas obtidas, a empresa direcionou as vendas a brasileiros da região Sul, vendeu colônias de aproximadamente 25 hectares e forneceu uma estrutura mínima para o começo da colonização. A seguir, o empreendimento colonial se consolidou por meio de uma rede de sociabilidade, envolvendo relações de parentesco, compadrio e alianças políticas das mais diversas. Essa forma de organização marca as paisagens humanizadas no município, a partir de experiências e expectativas vivenciadas e fixadas nas representações coletivas dos migrantes que participaram do processo.

Desse processo resulta uma nova configuração das relações fronteiriças entre os dois países, incluindo dinâmicas demográficas particulares na região. A isso, Albuquerque acrescenta: 
O deslocamento de milhares de trabalhadores para a construção da hidrelétrica de Itaipu e a indenização de vários camponeses que viviam no lugar do futuro lago de Itaipu também contribuíram para aumentar o fluxo migratório para o Paraguai na década de 1970 e 1980 (ALBUQUERQUE, 2009, p. 142).

Constata-se ainda que a migração para o Paraguai se configura também como alternativa de fuga para famílias atingidas pela Usina Hidrelétrica de Itaipu. Esta e outras situações de evasão são percebidas em diversos relatos de migrantes que se fixaram em Santa Rita, os quais descrevem as dificuldades vividas como pequenos produtores no Brasil, tais como: terras pouco férteis e de alta inclinação do terreno em áreas serranas; grande número de membros nas famílias; falta de espaço e de trabalho para novas gerações etc. Para pessoas assim, as dificuldades enfrentadas em uma região percebida como "selva" ou "sertão", inicialmente sem nenhuma infraestrutura, foi uma alternativa positiva em relação às dificuldades enfrentadas no Brasil e uma oportunidade de melhoria de vida no Paraguai.

Além dos sulistas, migrantes de outras partes do Brasil também se fixaram no Oriente paraguaio, embora em menor número. Conforme apontado por Souchaud (2007), a maior parte dessas pessoas foi para o país como mão-de-obra para abrir e derrubar a mata, limpar os terrenos e também para a produção de menta, trabalhando como peões ou arrendatários. Normalmente vistos por sulistas como "nortistas", esse contingente populacional estava em situação de subalternidade diante da assimetria observada em relação a gaúchos, catarinenses e paranaenses donos de terra. Muitos retornaram ao Brasil, diante da perda de postos de trabalho no momento em que ocorreu a mecanização agrícola na região. Nas narrativas registradas na região, durante os trabalhos de campo, esse coletivo não é lembrado como "pioneiro".

Discute-se, ademais, o número de brasileiros que se fixaram na região entre a década de 1970 e meados dos anos 1980, variando as estimativas entre 300.000 e 400.000 pessoas (SILVA, 2005, p. 171). 
Souchaud (2007) e Sprandel (1992), referindo-se ao fluxo de brasileiros no Paraguai até o decênio de 1990, chegam à estimativa de 500.000 indivíduos. Albuquerque (2009, p. 139), por sua vez, aponta que, de acordo com "os dados do Ministério das Relações Exteriores, em 2002, dos 545.886 brasileiros que se encontravam nos países da América do Sul, 459.147 estavam no Paraguai". Carrón e Silva (2006), por outro lado, afirmam que provavelmente essas estimativas são exageradas, pois à época o número de brasileiros no Paraguai não superaria 200.000, ainda que seja no momento de maior migração. Apesar do número aparentemente incerto de brasileiros residentes no Paraguai, ressalta-se que, pelo censo de 2012, a população total do país era de aproximadamente 6 milhões de pessoas (DGEEC, 2012).

\section{Figura 2 - RePresentação CARTOGRÁfica Sobre A Migração de}

brasileiros do Sul para o Paraguai e outras regiões do Brasil.

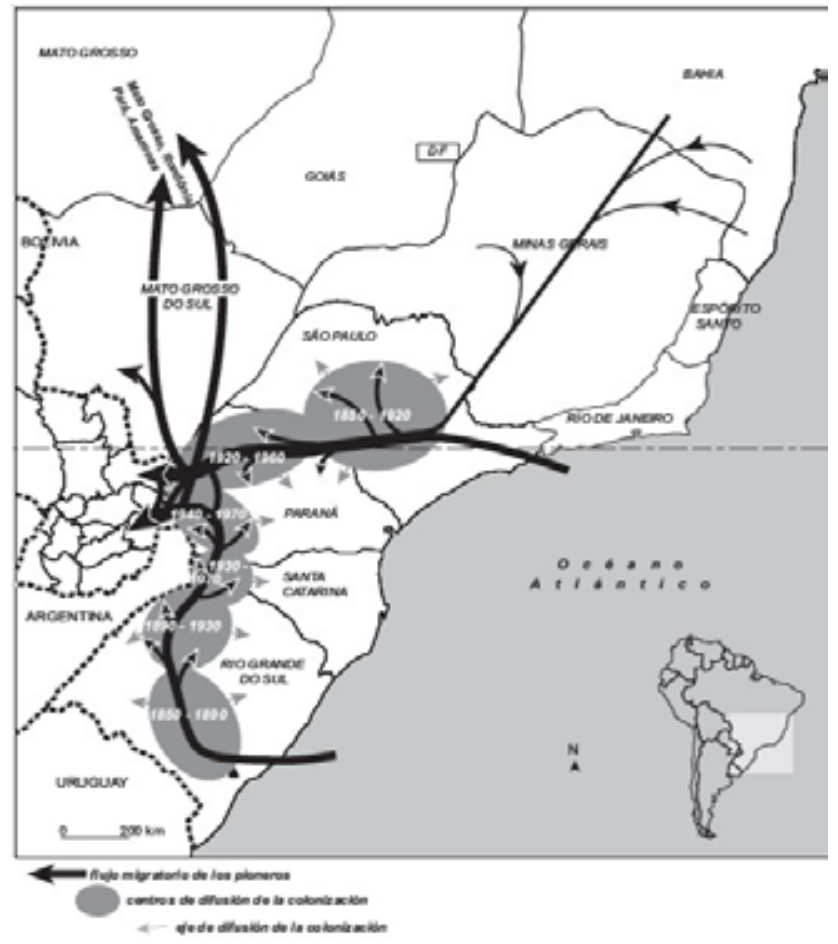

Fonte: Souchaud (2007, p. 104). 
Em linhas gerais, a grande quantidade de terras disponíveis a preços baixos, as portas abertas do Paraguai à migração, o mercado de soja em expansão no mundo e a experiência com a produção agrícola de pessoas do Sul do Brasil, fizeram com que brasileiros se movimentassem de acordo com as possibilidades de expansão das fronteiras agrícolas. Verifica-se que a conjuntura do mercado global e local e os incentivos do governo central favoreceram a migração e a fixação de um grande número de brasileiros no Paraguai. Sobre esse processo, Souchaud aponta que para a expansão da agricultura:

La solución imaginada reside en un llamado a la inmigración de campesinos extranjeros, detentores de una experiencia pionera y de una agricultura moderna. La retórica oficial precisa que la instalación de migrantes en la zona fronteriza oriental sea susceptible de iniciar un proceso de modernización de la agricultura. Esto sería seguido de una integración de la zona periférica que aseguraría la transferencia de habitantes de la región central hacia la región pionera. El proyecto en sí mismo no tiene nada de innovador; en contrapartida, las modalidades de su aplicación sí, Stroessner va a convocar a los enemigos de ayer para llevar a cabo este amplio proyecto de integración. (SOUCHAUD, 2007, p. 91).

O autor denuncia que o processo de migração, legitimado pelo governo Stroessner, atende a aspirações econômicas e políticas, embora afete negativamente a distribuição de terras aos nacionais. $\mathrm{O}$ procedimento que previa os colonos paraguaios como principais beneficiários acabou por favorecer os colonos brasileiros devido a formas fraudulentas de distribuição da terra pelo Estado. Esta crítica é corroborada por Albuquerque (2009), ao revelar que os principais prejudicados são indígenas e campesinos paraguaios. Vázquez (2006) ainda aponta que a política de incentivo à migração brasileira provocou o deslocamento forçado dos colonos nacionais e gerou uma concentração da propriedade agrícola no país. E, também, Foguel e Riquelme (2005, p. 9), mostram "como el modelo productivo en cuestión genera gran riqueza para pocos y pobreza para muchos", ao denunciar a exploração estrangeira a partir do agronegócio. 
Odiscurso de vazio demográfico na região Oriental do Paraguai e de progresso a partir da agricultura é construído e legitimado nessa época pelo governo paraguaio, e continua presente nas narrativas dos colonos migrantes estabelecidos na região, conforme apontado anteriormente. Diante da situação assinalada, apresenta-se uma representação cartográfica oficial do Paraguai com a indicação dos territórios de povos indígenas, cuja imagem serve para desconstruir a ideia de vazio demográfico justificada para a colonização recente.

Figura 3 - INdicaÇÃo oficial de ÁREAS OCUPADAS POR POVOS INdígenaS na República do Paraguai, segundo o INDI - Instituto Paraguayo DEL INDÍGENA.

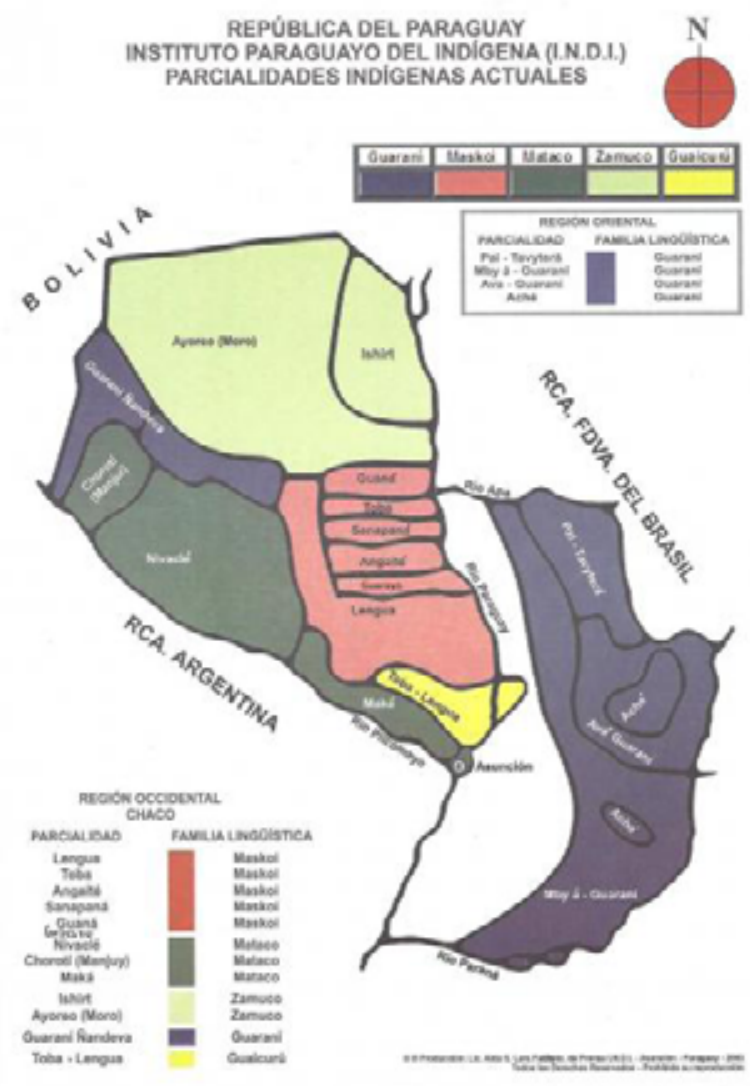

Fonte: Instituto Paraguayo del Indigena (2015). 
Autores como Figueredo e Miguel (2015) demonstram que a pequena presença populacional paraguaia nas franjas fronteiriças teria justificado a inexistência de contestação para a instalação dos migrantes e, por conseguinte, o posterior avanço dos brasileiros. Esta constatação, contudo, não deve ser desassociada do contexto de sua época, haja visto que o país vivia sob um regime militar, cujo modus operandi não estava vinculado à consulta pública a coletivos atingidos por processos de colonização. Sobre o assunto, assim registra Souchaud (2007, p. 171): "El territorio constituido es para ellos [brasileros] un apéndice del espacio económico del Brasil meridional y a la vez un territorio de la identidad gaúcho o sulista, dentro del cual la cultura paraguaya es minoritaria". Entretanto, o referido autor adverte que com o processo de democratização do Paraguai, a partir da década de 1980, cresce no país um sentimento antibrasileiro e, ao mesmo tempo, a organização dos campesinos nacionais para a reivindicação de terras. As próprias elites nacionais estimulam este sentimento nos meios de comunicação, o que faz parte de uma estratégia nacionalista para desviar a atenção dos movimentos étnicos e sociais em relação às suas próprias ações e contradições colonialistas. No entanto, a crítica apresentada não exclui o fato de que muitas vozes silenciadas durante a ditadura Stroessner passaram a ecoar no âmbito da luta pela terra no país.

A partir da redemocratização do Paraguai, foi editada a Lei n. 978/1996 para regulamentar as migrações, bem como inserir restrições e barreiras político-administrativas do Estado em relação à presença brasileira: "El poder paraguayo, a pesar de las apariencias, sí ejerce un control sobre este espacio, imponiendo ciertas reglas a las poblaciones de inmigrantes y reservándose el derecho a expulsarlos" (SOUCHAUD, 2007, p. 258). O autor destaca que nessa lei há obstáculos que dificultam a legalização da situação dos migrantes, situação esta que propicia e estimula a ilegalidade e faz crescer a instabilidade daquela população. Exemplo disso é a dificuldade enfrentada por migrantes brasileiros 
para regularizar a documentação civil e patrimonial, possível apenas em Assunção, capital do país. Migrantes da região citam corrupção e extorsão como práticas corriqueiras naquele momento. Esta conjuntura gera um fluxo de retorno ao Brasil de migrantes em situação de maior vulnerabilidade, como arrendatários e pequenos produtores.

A mecanização da agricultura, com a concentração de terra, também levou a um retorno de migrantes. Em relação à concentração de terras no Paraguai, Carrón e Silva (2006, p. 15), baseando-se na mostra agropecuária realizada em 2002 pelo Ministério de Agricultura y Ganadería do Paraguai, sugerem que propriedades com menos de 100 hectares estariam destinadas a desaparecer diante do avanço da monocultura da soja: "Así, la soja, que ya expulsó del agro a decenas de miles de pequeños campesinos paraguayos, también expulsa a colonos brasileños que trabajan en pequeña escala". Os autores entendem que o resultado da situação seria a migração rural-urbana dentro do Paraguai ou o retorno de pequenos e médios produtores brasileiros ao seu país de origem. Dessa situação resultam conflitos entre grandes proprietários de terra e a população local, o que afeta negativamente o meio ambiente, pequenos produtores, comunidades campesinas e povos indígenas (VÁZQUEZ, 2006). Significa dizer que a pujança econômica, especialmente aquela decorrente da monocultura da soja, está no epicentro de relações sociais de poder, exploração e tentativas de dominação que marcam o colonialismo no Oriente paraguaio. Soma-se a isso a ausência eficaz e moralizadora do Estado e das elites nacionais na própria organização territorial do país.

\section{Conflitos na Região de Colonização}

Os conflitos gerados a partir da colonização recente no Paraguai estão relacionados, também, à gradual concentração de terra e, consequentemente, à formação de latifúndios. Geralmente foram 
silenciados durante o governo militar, mas começam a ganhar força e notoriedade a partir do processo de democratização nos anos 1980:

No será hasta mediados de los años ochenta cuando las organizaciones campesinas comiencen a rearticularse. Algunas de ellas como el Movimiento Campesino Paraguayo (MCP), fundada en 1980, siguen presentes en la actualidad. La Coordinación Nacional de Organizaciones Campesinas (CONAPA) se constituye en 1985, y en 1986 lo hace la Organización Nacional Campesina (ONAC). Durante la dictadura, las ocupaciones eran escasas y los grupos campesinos que optaban por esta modalidad de presión eran violentamente reprimidos (SITUACIÓN..., 2011, p. 49).

Neste sentido, o alargamento das fronteiras entre Brasil e Paraguai aponta não apenas para conflitos fundiários, mas também a limites étnicos e socioculturais:

Nesses cenários específicos de tensões relacionadas à terra, ao meio ambiente e ao poder político local, a fronteira "brasiguaia" pode ser vista como um campo de conflitos de classes, disputas étnicas, tensões nacionalistas e choque entre a civilização capitalista ocidental e as culturas camponesas e indígenas. As fronteiras podem ser entendidas aqui como marcos de diferenças sociais (ALBUQUERQUE, 2009, p. 147).

Portanto, além de conflitos pela posse da terra, disputas simbólicas - em acepção a Bourdieu (2001), que define poder simbólico como uma possibilidade de produzir e impor uma visão de mundo legítima - formam o cenário das relações estabelecidas entre brasileiros e paraguaios na zona de colonização. Exemplo disso foi o conflito que ganhou grande repercussão em 1985, quando mais de mil famílias de migrantes retornaram ao Brasil com apoio da Comissão Pastoral da Terra (CPT) e do Movimento dos Trabalhadores Rurais Sem Terra (MST) (BATISTA, 1990; SPRANDEL, 1992; CORTÊS, 1994; 
COSTA, 2013; e outros). Neste contexto surgiu o temo "brasiguaio", inicialmente empregado para se referir a esses coletivos.

As disputas simbólicas se evidenciam a partir do uso do termo "brasiguaio" de acordo com interesses de definição do Outro. Com o passar dos anos, o termo passou a ter uma notação polissêmica, ou seja, a ser empregado para se referir a múltiplas situações e propósitos, tais como: a de brasileiros no Paraguai; brasileiros que voltaram do Paraguai ao país de origem; descendentes de brasileiros e paraguaios; e assim por diante. Priori e Klauck (2010, p. 96), por exemplo, defendem a ideia de que os brasiguaios "são os pobres, os oprimidos, os sem direitos trabalhistas e sociais, enfim, aqueles sem pátria e sem esperança". Contudo, Haesbaert e Santa Barbara (2001) apontam que o termo é cada vez mais utilizado de forma ampla, porém preconceituosa, motivo pelo qual defendem que o vocábulo deixe de ser estigmatizado.

Neste caso em específico, entende-se que ser ou não "brasiguaio" tem a ver com uma categoria que passou a se desvincular de sua origem conceitual, qual seja, fazer referência a camponeses pobres que retornavam do Paraguai para o Brasil. Tornou-se uma forma de estabelecer identidades relacionais e situacionais, valendo-se aqui de uma acepção a Barth (2000) e Hall (2006). O assunto também é verificado por Nascimento, em trabalho intitulado Yo soy paraguayo, chamigo: "A categoria brasiguaio seria manipulada e ressignificada [...] para servir de instrumento discursivo que objetiva dar sentido e significado às relações socioculturais estabelecidas no cotidiano da vida prática" (NASCIMENTO, 2012, p. 99). Considerando a contribuição de Sprandel (2006) sobre o tema, percebe-se que a categoria tem sido politicamente usada para homogeneizar distintos coletivos, os quais possuem historicidades e características econômicas, políticas e socioculturais específicas. Serve, inclusive, para construir representações estereotipadas acerca do migrante brasileiro: ora é 
percebido como alguém que teria sido expulso do Paraguai e estaria envolvido em conflitos pela posse da terra no Brasil, ora é citado como membro de um grupo de empresários ricos e imperialistas que estariam a ceifar direitos dos nacionais paraguaios (SPRANDEL, 2006, p. 137), dentre outras imagens homogeneizantes.

Durante o trabalho de campo em Santa Rita, percebeu-se que a população em geral não usa o termo brasiguaio, pois o mesmo está estigmatizado e é usado apenas de forma pejorativa. Em suma, por meio deste vocábulo verificam-se relações conflituosas expandidas para questões simbólicas referentes à representação e à identidade nacional do Outro. Este Outro, por seu turno, também é constituído por pessoas que fazem parte da segunda ou terceira geração de descendentes de migrantes, as quais estão territorializados e possuem sentimento de pertencimento ao Paraguai. Sentir-se paraguaio, contudo, não significa ruptura e aculturação em relação ao Brasil, país de origem de seus ancestrais, haja visto que uma identidade nacional não exclui a outra, necessariamente.

Ocorre que cada indivíduo possui uma realidade e está inserido neste processo de acordo com suas ações e experiências de vida em sociedade, sua memória compartilhada (JELIN, 2001). Esta pluralidade de particularidades faz com que o processo de migração seja algo complexo e não linear, ligado a uma perspectiva de tempo não naturalizado, valendo-se aqui dos aportes de Fabian (2013).

Como tentativa de sistematizar a história da migração brasileira ligada à colonização recente no Paraguai, ainda que relegada ao campo das hipóteses, apresenta-se três movimentos ligados a este processo. O primeiro está vinculado a grandes empresas colonizadoras e migrantes com menor poder econômico que vão trabalhar como empregados na abertura das terras colonizadas. De acordo com Souchaud (2007), a maioria dessas pessoas seria proveniente de regiões onde há ou havia lavouras de café nos estados de São Paulo e Paraná, 
e grande parte não teria conseguido se fixar no Paraguai. O segundo - que acontece concomitantemente com o primeiro - está associado a pessoas vindas do Sul do Brasil, inseridas no processo de expansão das fronteiras agrícolas. Parte significativa delas possui poder econômico para comprar terras e investir na agricultura. $\mathrm{O}$ terceiro ocorre como contrafluxo, pois enquanto muitos migrantes voltam para o Brasil, por conta da mecanização da agricultura e concentração de terras, uma leva de indivíduos tidos como mão-de-obra qualificada se desloca para o país vizinho.

No decorrer dos anos, a contar, sobretudo, da década de 1990, muitos migrantes deixam de serem colonos estabelecidos no campo e se incorporam a novas redes urbanas, o que sugere a existência de êxodo rural e/ou a transformação do campo em cidade. Também ampliaram as relações sociais estabelecidas em solo paraguaio, conforme explicado na sequência:

Si el paisaje agrícola y los actores del sistema de la soja son, en esta zona, mayoritariamente brasileños, las ciudades que alimentan este sistema también se caracterizan por esa influencia, la cual no se refleja exclusivamente en el predominio de idioma portugués y de la nacionalidad brasileña, sino que se reproduce en varios ámbitos no productivos. La mayoría de los poderes locales, especialmente el más fuerte, la Municipalidad con la figura del intendente y los miembros de la Junta Municipal, están bajo el control del sistema brasileño representado en gran parte por los "brasiguayos", es decir, inmigrantes brasileños con nacionalidad paraguaya (VÁZQUEZ, 2006, p. 60).

Além disso, o mencionado autor assim explica a transformação do espaço no Oriente paraguaio, incluindo a construção de cidades à moda brasileira:

El proceso de territorialización de los colonos brasileños en esta región se desarrolla sobre la reproducción total del sistema del país vecino, impidiendo el proceso de 
integración de los mismos al sistema socioeconómico y cultural paraguayo, alterando los roles de los migrantes quienes no solo no se integran ni aceptan el funcionamiento del país que les acoge, sino que logran imponer su idioma, sus preferencias culturales, gastronómicas y religiosas e imprimir una dinámica territorial propia (VÁZQUEZ, 2006, p. 61).

A situação indicada também resulta de relações sociais transnacionais, a envolver poderes entre Estados-nações, motivo de conflitos. Seguindo a interpretação do referido autor:

Todo eso es el resultado directo de la inexistencia de una política y de planes de ordenamiento y desarrollo territorial para estas zonas. Lo cual es aprovechado por los agricultores e inmigrantes brasileños en general, que disponen además de un apoyo incondicional de sus autoridades en Brasil y de sus representantes en Asunción, defendiendo los intereses de sus ciudadanos y creando la imagen de Paraguay como país de inmigrantes que construyen el país. Expresiones como "paraguayos no son solo los que nacen, sino también los que trabajan en Paraguay" sirven de muestra para ilustrar la justificación del discurso que apoya, alimenta y racionaliza económicamente la inmigración brasileña (VÁZQUEZ, 2006, p. 61).

Ao expressar o apoio de autoridades brasileiras e paraguaias à ação de territorialização dos migrantes brasileiros na região, o referido autor aponta para uma ação de colonialismo, evidenciando uma violência simbólica. Percebe-se ainda a construção da imagem de que o migrante brasileiro seria responsável pelo desenvolvimento do Paraguai, ao passo que o nacional não teria participação significativa na conformação desta situação histórica. No caso, a perspectiva evolucionista de progresso é recorrida amiúde para justificar e explicar processos sócio-históricos dos mais complexos, os quais resultam em inúmeros conflitos sociais. 
No caso da cidade de Santa Rita, vale lembrar que se trata de uma área urbana com marcante presença brasileira. Esta situação é percebida, por exemplo, no uso cotidiano do idioma português, edificações semelhantes às existentes na região Sul do Brasil, gastronomia sulista, eventos culturais e também na atuação do poder local. Neste espaço de migração, conflitos dos mais diversos, incluindo a disputa pela posse de terras e a luta por reforma agrária são amiúde percebidos como distantes da realidade local. Entretanto, até pouco tempo havia acampamentos de campesinos na localidade - sobretudo durante o governo de Fernando Lugo (2008-2012), deposto por um golpe parlamentar de Estado - a reivindicar terras consideradas malhabidas, isto é, obtidas de forma irregular. Alguns interlocutores apontaram a importância do apoio dado aos migrantes pelo então intendente de Santa Rita, com vistas a impedir o aumento de conflitos fundiários no município. Durante os trabalhos de campo, foi ainda constatada a existência de uma ocupação urbana de indígenas que teriam vindo de diferentes localidades para a cidade, os quais estariam ali em busca de emprego, o que denota a situação de exclusão dos povos originários no contexto local. Além disso, outros conflitos ocorrem de forma velada na região, mas podem ser observados em diversas representações locais, como ocorrem com o uso do idioma português em placas comerciais, e em feiras e exposições voltadas para o agronegócio. Nota-se, dessa forma, um conjunto de estratégias políticas para licenciar conflitos dos mais diversos, com o propósito de construir uma imagem de harmonia social e solidariedade para região colonizada.

Além das situações de conflito aqui apontadas, majoritariamente a envolver migrantes brasileiros, faz-se necessário explicar que movimentos campesinos ocupam propriedades de outros estrangeiros no Oriente do país (alemães, árabes, chineses, coreanos, estadunidenses etc). Reivindicam terras transformadas em latifúndios 
e propriedades privadas de paraguaios natos, isto é, de membros das elites nacionais, principalmente fazendas de ex-militares que acumularam riquezas e adquiriram grandes áreas durante o governo Stroessner (ALBUQUERQUE, 2009). Consequentemente, muitos proprietários de terras, nacionais e estrangeiros, se armam contra o que consideram invasões; não raramente fazem isso através da contratação de pistoleiros e grupos paramilitares que agem contra movimentos étnicos e sociais.

La faceta más conocida de la represión contra los movimientos campesinos son los hostigamientos, ataques y asesinatos cometidos por cuerpos policiales, parapoliciales y por grupos privados armados, en contra de representantes campesinos. La persecución judicial a los dirigentes es la otra cara del intento por desarticular a las organizaciones (SITUACIÓN..., 2011, p. 85).

Ações desse tipo têm sido denunciadas e geralmente contam com a cumplicidade de agentes do Estado, como demonstrado a seguir:

Así, el principal problema que cae sobre las comunidades campesinas e indígenas es la corrupción de los organismos del Estado en el contexto del gran poder corruptor de los empresarios agroindustriales. La defensa de los intereses campesinos sigue dependiendo de su capacidad de organización y de tejer alianzas estratégicas, incluso dentro del gobierno (SITUACIÓN..., 2011, p. 57).

Em vista disso, constata-se que a colonização implantada na época do governo Stroessner, durante um regime de exceção, segue beneficiada por estruturas de poder e tentativas de dominação que se ramificam no Estado e na sociedade nacional do Paraguai. Neste contexto, alguns estrangeiros, principalmente brasileiros, estão diretamente vinculados a uma elite de migrantes com poderes de exclusão, considerados pelos nacionais como invasores e exploradores. Em sua maioria são proprietários de terras e empresas que atuam no ramo do agronegócio. Por outro lado, ressalta-se que muitos brasileiros 
também são excluídos do processo de modernização da agricultura, como dito anteriormente, e fazem parte de frentes que ultrapassam fronteiras nacionais e criam outros limites entre os indivíduos que vivem na região.

\section{Conclusão}

A colonização recente no Paraguai é tema relevante e demasiado complexo sob vários aspectos e para diferentes campos do conhecimento. Por este motivo, no decorrer do artigo deu-se atenção a relações sociais e disputas de poder a envolver brasileiros e paraguaios territorializados no país vizinho. Esta situação histórica é verificada, sobretudo, a partir da década de 1970, no contexto das ações do colonialismo interno durante ditaduras implantadas em países que no tempo presente fazem parte do MERCOSUL. Resulta de ações ligadas às frentes de expansão das fronteiras agrícolas na porção Oriental do Paraguai, onde está localizado o município de Santa Rita e existe forte presença de migrantes brasileiros e descendentes.

Buscou-se, portanto, mostrar que o processo de colonização está ligado a situações históricas particulares e a novas configurações regionais, registradas na segunda metade do século XX. Na época, tanto o Brasil quanto o Paraguai viviam sob ditaduras militares e a experiência de um país serviu de modelo para o outro no que se refere às frentes de expansão das fronteiras agrícolas. Por isso a "Marcha para el Este", implantada no Paraguai durante o governo Stroessner, foi concebida a partir das experiências da "Marcha para Oeste", realizada no Brasil na época do governo Vargas.

Neste sentido, a participação de brasileiros tem promovido a colonização oficial e o desenvolvimento da economia paraguaia, bem como estimulado a existência e a manutenção de conflitos entre estrangeiros e nacionais pela posse de terras. Isso ocorre, 
primeiramente, devido ao poder político e econômico de migrantes, os quais participam de uma rede transnacional de relações sociais da qual fazem parte agentes do Estado Paraguaio e membros das elites nacionais. Disso resulta o atendimento preferencial de seus interesses frente às reivindicações de direito por parte de indígenas e campesinos organizados em movimentos étnicos e sociais. A situação apontada também está ligada a conflitos que envolvem identidades individuais e coletivas e representações estereotipadas e generalizantes sobre o Outro, aquele que é diferente em relação a quem o percebe como nacional ou estrangeiro.

Sobre a colonização existem ainda diversos discursos, tanto na oralidade quanto nas bibliografias, cada um deles buscando legitimar um ponto de vista, em uma constante disputa de poder.

Em suma, a partir de um olhar que procura estabelecer um estranhamento sobre indivíduos e coletivos que participam do processo de colonização, constata-se que os conflitos entre eles são historicamente de ordem política, econômica e sociocultural. Isso porque na parte Oriental do país, brasileiros e paraguaios estão inseridos em um sistema estruturante de relações sociais de poder, exploração e tentativas de dominação. Nesse processo ambíguo, fica evidente que o poder que rege a colonização não é apenas o poder político do governo paraguaio, mas também o agronegócio, o poder econômico. Neste contexto, pobres são excluídos, marginalizados e colocados na condição de subalternidade, ao passo que ricos têm seus interesses atendidos, independentemente de sua origem nacional.

\section{REFERÊNCIAS}

ALBUQUERQUE, José Lindomar C. A dinâmica das fronteiras: deslocamento e circulação dos "brasiguaios" entre os limites nacionais. Horizontes Antropológicos, Porto Alegre, v. 15, n. 31, p. 137-166, 2009. 
BACK, Andressa. Multiplicidade na fronteira: o fenômeno das identidades transfronteiriças em Santa Rita no Paraguai. 2014. Dissertação (Mestrado em Ciências Sociais) - Universidade Estadual do Oeste do Paraná, Toledo, 2014.

BALANDIER, Georges. A noção de situação colonial. Tradução de Nicolás Nyimi Campanário. Cadernos de Campo, São Paulo, n. 3, p. 107-131, 1993.

BARTH, Fredrik. O guru, o iniciador e outras variações antropológicas. Tradução de John Cunha Comeford. Rio de Janeiro: Contra Capa, 2000.

BATISTA, Luiz Carlos. Brasiguaios na fronteira: caminhos e lutas pela liberdade. 1990. Dissertação (Mestrado em Geografia Humana) - Universidade de São Paulo, São Paulo, 1990.

BOURDIEU, Pierre. O poder simbólico. 4. ed. Rio de Janeiro: Beltrand Brasil, 2001.

CARRÓN, Juan M.; SILVA, Marcia Regiana. La frontera Paraguay-Brasil, integración económica y desintegración social. Población y Desarrollo, Asunción, n. 33, p. 9-22, 2006.

COOPER, Frederick. Colonialism in question: theory, knowledge, history. Berkeley: University of California Press, 2005.

CORTÊZ, C. Brasiguaios: os refugiados desconhecidos. s. 1.. Brasil Agora, 1994.

COSTA, Jessica Ausier. As relações bilaterais Brasil-Paraguai e a problemática dos "brasiguaios". Revista Habitus, Rio de Janeiro, v. 7, n. 1, p. 56-71, 2009.

COSTA, Jessica Ausier. Fronteiras, migração e identidade: o fenômeno "brasiguaio". 2013. Dissertação (Mestrado em Relações Internacionais) - Pontifícia Universidade Católica do Rio de Janeiro, Rio de Janeiro, 2013.

DGEEC. Dirección General de Estadística, Encuestas y Censos. Anuario Estadístico del Paraguay 2012. Asunción, 2012.

FABIAN, Johannes. O tempo e o outro: como a antropologia estabeleceu seu objeto. Tradução de Denise Jardim Duarte. Petrópolis: Vozes. 2013.

FABRINI, João E. Conflitos de terra na fronteira Brasil-Paraguai e luta dos brasiguaios. In: ENCONTRO NACIONAL DE GEOGRAFIA AGRÁRIA, 21., 2012, Uberlândia. Anais... Uberlândia, 2012. Disponível em: <http://www.lagea.ig.ufu.br/ xx1enga/anais_enga_2012/eixos/1015_1.pdf>. Acesso em: 3 fev. 2015.

FANON, Franz. Os condenados da terra. Tradução de Laurênio de Melo. Rio de Janeiro: Civilização Brasileira, 1968.

FIGUEREDO, Oscar A. T.; MIGUEL, Lovois A. A modernização da agricultura e os brasiguaios no Paraguai. Disponível em: <http://www.sober.org.br/palestra/5/970. pdf $>$. Acesso em: 3 fev. 2015. 
FOGEL, Ramón; RIQUELME, Marcial (Org.). Enclave sojero, merma e soberanía y pobreza. Asunción: CERI, 2005.

GONZÁLEZ CASANOVA, Pablo. Colonialismo interno (uma redefinição). In: BORON, Atílio A. et al. (Org.). A teoria marxista hoje: problemas e perspectivas. Buenos Aires: CLACSO, 2006. p. 395-419.

GREGORY, Valdir. Os eurobrasileiros e o espaço colonial: migrações no Oeste do Paraná (1940-1970). Cascavel: Edunioeste, 2002.

HAESBAERT, Rogerio; SANTA BARBARA, Marcelo de Jesus. Identidade e migração em áreas transfronteiriças. GEOgraphia, Rio de Janeiro, 2001. Disponível em: <http://www.uff.br/geographia/ojs/index.php/geographia/article/ download/53/51>. Acesso em: 3 fev. 2015.

HALL, Stuart. A identidade cultural na pós-modernidade. 11. ed. Rio de Janeiro: DP\&A, 2006.

HENRIQUES, Isabel Castro. Colónia, colonização, colonial e colonialismo. In: Sansone, Livio; FURTADO, Cláudio (Org.). Dicionário crítico das ciências sociais dos países de fala oficial portuguesa. Salvador: EDUFBA, 2014. p. 45-58.

INSTITUTO PARAGUAYO DEL INDIGENA. Parcialidades indígenas actuales. Disponível em: <http://www.indi.gov.py/pagina/18-pueblos-indigenas.html >. Acesso em: 10 jul. 2015.

JELIN, Elizabeth. Los trabajos de la memoria. Ciudad de México: Siglo Veintiuno Editores, 2001.

LANDER, Edgardo (Org.). A colonialidade do saber: eurocentrismo $e$ ciências sociais: perspectivas Latino-Americanas. Buenos Aires: CLACSO, 2005.

LOOMBA, Ania et. al. (Ed.). Postcolonial studies and beyond. London: Duke University Press, 2005.

MAPAS DEL MUNDO. Mapa politico de Paraguay. Disponível em: <http://espanol. mapsofworld.com/continentes/sur-america/paraguay/paraguay-mapa.html>. Acesso em: 10 jul. 2015.

MARTINS, Leticia Miller. Um estudo sociolingüístico da comunidade dos imigrantes brasileiros em Santa Rosa del Monday - Paraguai. 1996. Dissertação (Mestrado em Linguística) - Universidade Estadual de Campinas, Campinas, 1996.

NASCIMENTO, Valdir Aragão do. "Yo soy paraguayo, chamigo": breve estudo sobre a identidade no Paraguai. 2012. Dissertação (Mestrado em Antropologia) Universidade Federal da Grande Dourados, Dourados, 2012.

OLIVEIRA, Roberto Cardoso. A sociologia do Brasil indígena. Rio de Janeiro: Tempo Brasileiro; Brasília: Editora UnB, 1978. 
PRIORI, Angelo; KLAUCK, Roberto Carlos. O retorno dos brasiguaios. Revista Espaço Acadêmico, Maringá, v. 10, n. 109, p. 95-102, 2010.

PUJADAS, Joan J. La etnografía como practica de campo. In: PUJADAS, Joan J.; D'ARGEMIR, Dolors C.; ROCA, Jordi. Etnografia. Barcelona: Editorial UOC, 2012. p. $72-89$.

SAID, Edward W. Orientalismo: o oriente como invenção do ocidente. Tradução de Rosaura Eichenberg. São Paulo: Companhia das Letras, 2007.

SILVA, Henrique M. Teuto-brasiguaios no oriente paraguaio: alguns apontamentossobre as condicionantes históricas da formação de uma fronteira de caráter binacional. Diálogos, Maringá, v. 9, n. 3, p. 167-184, 2005.

SITUACIÓN de los derechos humanos en el oriente paraguayo en 2009: conflicto por la imposición de un modelo cultural y agroindustrial. 2011. Disponível em <https://investigaccionddhh.files.wordpress.com/2011/12/3conflicto_por_ imposiciocc81n_modelo_cultural_y_agroindustrial.pdf $>$. Acesso em: 03 fev. 2015.

SMITH, Linda Tuhiwai. Descolonizing methodologies: research and indigenous peoples. London: Zed Books Ltd; Dunedin: University of Otago Press, 2005.

SOUCHAUD, Sylvain. Geografía de la migración brasileira em Paraguay. Asunción: Editorial UNFPA, 2007.

SPRANDEL, M. A. Brasiguaios: conflito e identidade em fronteiras internacionais. Dissertação de Mestrado em Antropologia Social -Museu Nacional, Universidade Federal do Rio de Janeiro, Rio de Janeiro, 1992.

SPRANDEL, Marcia Anita. Brasileiros na fronteira com o Paraguai. Estudos Avançados, São Paulo, v. 20, n. 57, p. 137-156, 2006.

SZEKUT, Andressa; EREMITES, Jorge de Oliveira. Memória e identidade em um espaço de migração: fronteiras em Santa Rita, Alto Paraná, Paraguai. Revista História em Reflexão, São Paulo, v. 9, n. 18, jul./dez. 2015.

THÉRY, Hervé. La vague déferlante du soja brésilien. M@ppemonde, n. 74, p. 1-7, 2004. Disponível em: <http://mappemonde.mgm.fr/num2/articles/art04204.pdf>. Acesso em: 10 jul. 2015.

VÁZQUEZ, Fabricio. Territorio y población: nuevas dinámicas regionales en el Paraguay. Asunción: ADEPO, 2006. (Serie Investigaciones, Población y Desarrollo, v. 3). 